\title{
Aplicativo de Corrida Compartilhada como Infraestrutura: Por uma nova forma de compreender a circulação de pessoas
}

\author{
Álvaro Prado Aguiar Tavares ${ }^{a}$
}

O presente artigo visa analisar como as infraestruturas dos aplicativos de corrida compartilhada permitem um tipo específico de movimento pela malha urbana. Assim, através de uma revisitação de como a questão da infraestrutura se faz presente em alguns trabalhos da Antropologia Urbana, discuto como a infraestrutura dos aplicativos colocam uma série de novas questões para a compreensão da mobilidade (como a ideia de que os motoristas por aplicativo, imersos em uma situação de precariedade, se movem de forma alienada pela cidade) que em muito transbordam as análises prévias sobre esta temática. Ademais, a partir de um específico contexto etnográfico, mostro como uma perspectiva a partir das cidades do sul global pode levantar novas questões acerca da contraditória relação entre os motoristas e os aplicativos de corrida que os interpelam. Por fim, sugiro que a dinâmica de distribuição de informações dessas infraestruturas vai na contramão de uma vivência democrática da cidade.

Infraestrutura, Mobilidade, Precariedade, Sul global.

Diremos, então, que é o coletivo no seu todo que se define daqui por diante como uma experimentação coletiva. Experimentação do quê? Dos vínculos e dos desvínculos que the permitirão, a um dado momento, encontrar os candidatos à existência comum, e decidir se podem se situar no interior do coletivo ou se devem, com um processo bem formado, tornar-se inimigos provisórios. É o conjunto do coletivo que fará a si a pergunta para saber se pode coabitar com tal ou qual, e a que preço; quem investigará as provas, permitindo-lhe decidir se teve ou não razão de operar a adição ou subtração. As deliberações do coletivo não devem mais ser suspensas ou abreviadas por um conhecimento definitivo, já que a natureza não dá mais um direito que seja contrário ao exercício da vida pública (Bruno Latour 2019:20).

a Mestrando em Antropologia pelo Programa de Pós Graduação em Antropologia (PPGA-UFPE). Email: alvaroaguiar197@gmail.com. 
Compreender a mobilidade urbana exige identificar as infraestruturas que as tornam possíveis. Estas contribuem tanto na formulação dos tipos de movimentos que são desejáveis quanto aqueles que são indesejáveis dada a sua formulação específica por poderes estatais ou privados (muitas vezes na turva associação de ambos). Nesse sentido, a ênfase na infraestrutura nos ajuda a entender qual a forma das solidariedades sociais que emergem a partir da interação de uma gama de arranjamentos sociais com as infraestruturas que conduzem seus movimentos pela malha urbana.

Se colocarmos uma lente sobre essa temática em alguns trabalhos da Antropologia Urbana veremos uma variedade de desdobramentos dessa questão, seja a partir da infraestrutura dos rádios dos motoristas de táxi (Rosa 2012) seja na infraestrutura dos shopping centers no que ficou popularizado como os rolezinhos (De Faria et al 2017). Assim, os vários trabalhos que discutem essas questões, mesmo que implicitamente, dão ênfase a como essas diferentes infraestruturas concediam diferentes condições de emergência para solidariedades sociais e reivindicações políticas.

Uma nova latência foi dada a essa questão quando uma nova forma de mobilidade urbana ganhou abrangência no Brasil a partir de 2016, os serviços de corrida compartilhada. Aqui, trabalhadores que viam suas situações financeiras se complicarem a partir da crise econômica de 2016, encontravam nos serviços de empresas como a Uber e a 99 a possibilidade de suavizá-las. Tal realidade coloca no centro da questão da mobilidade uma nova infraestrutura, a saber os aplicativos de corrida e as formas pelas quais motoristas e passageiros interagem com ele. Esses aplicativos conduzem certos movimentos pela cidade ao enquadrar o tipo de informação que circula entre motoristas e passageiros de modo que informações como preço de corrida, local de chegada e destino das viagens, notas de passageiros e motoristas circulam a partir de um regime de distribuição de informações que acaba por condicionar movimentos pela cidade marcados por relações de trabalho precarizadas. 
Com a intenção de discutir essas questões mais detalhadamente, o presente artigo pretende primeiro mostrar sucintamente de que maneira a questão da infraestrutura se faz presente em dois trabalhos da antropologia urbana brasileira, revisitando suas observações etnográficas através de um horizonte infraestrutural. Em seguida, evidenciar como a infraestrutura dos aplicativos colocam uma série de novas questões para a compreensão da mobilidade que em muito transbordam as análises prévias sobre esta temática. Para tanto, irei discutir as especificidades do trabalho plataformizado através das questões elucidadas por Alex Rosenblat (Rosenblat \& Spark 2016; Rosenblat et al 2016; Rosenblat 2018) sobre a maneira como o aplicativo de corrida e seus algoritmos, ao enquadrarem o acesso às informações dos aplicativos, permitem um certo tipo de movimento pelas cidades. Em paralelo, discutirei como essas questões reverberam no contexto de crise econômica que se expande no Brasil a partir de 2014, através de entrevistas semi-estruturadas realizadas com motoristas de Uber da região metropolitana de Recife. A partir desse específico contexto etnográfico, colocarei em latência as contradições que envolvem a promessa das infraestruturas do aplicativo de corrida com a realidade de certos sujeitos marginalizados (Appel et al 2018:15). O intuito de colocar a pesquisa de Rosenblat em contato com a minha, evidenciando as aproximações e diferenças entre elas é o de mostrar como a diferença das cidades em que pesquisamos (ela, em cidades da Califórnia e de Nova York e eu, em Recife) possibilita a emergência de questões distintas acerca da infraestrutura do aplicativo. Nesse sentido, as realidades infraestruturais de cidades do cone sul (onde o contexto do Recife é um campo exemplar) com suas lógicas específicas de circulação urbana, de criminalidade e precariedades infraestruturais nos permitem identificar um locus determinado para se compreender as formas de interação entre motorista e aplicativo que podem não estar presentes em cidades localizadas no centro do capitalismo. Além dos regimes de circulação, se faz necessário entender também quais as situações político-econômicos que os motoristas localizados nessas cidades estão atravessando, 
uma vez que isso formula o contexto relacional dos motoristas com os aplicativos de viagens, fornecendo possibilidades específicas para a compreensão dessa questão. Assim, isso aparece como um esforço relevante para evidenciar como as vivências das cidades do sul podem nos fornecer horizontes heurísticos relevantes para se compreender uma infraestrutura que se tornou globalmente utilizada. Com esse fio condutor, mostraremos como a categoria infraestrutura pode mediar um entrecruzamento entre mobilidade urbana e precarização do trabalho. Por fim, trarei questionamentos sobre as considerações que veem na Uber a possibilidade de se democratizar o espaço urbano.

\section{Considerações metodológicas}

A fruição do argumento proposto aqui será o resultado de uma tensão entre, por um lado, uma revisão bibliográfica de relevantes trabalhos da antropologia urbana tendo como base uma leitura infrastrutural de suas análises e, por outro, as especificidades etnográficas de minha pesquisa de campo realizada em parceria com Benjamin Junge e como elas formulam determinados horizontes para se compreender as infraestruturas dos aplicativos de corrida. Esta pesquisa ${ }^{1}$ teve como objetivo central um esforço de associar o tipo de movimento urbano dos motoristas de Uber com as maneiras com que eles compreendem a política, baseando-se em entrevistas semi-estruturadas feitas no transcorrer das viagens realizadas ao longo da região metropolitana de Recife. Aqui, as vindouras eleições serviram de pano fundo para as questões que os motoristas desenvolviam enquanto questionamentos sobre suas rotinas como Ubers e sobre a situação Macropolítica do Brasil eram feitas. Nesse sentido, as falas dos motoristas são o resultado de um esforço feito por eles em encontrar relações entre as sucessivas crises que acontecem no Brasil desde meados de 2014 com as suas próprias precariedades enquanto motoristas por aplicativo. Assim, argumentamos que a maneira como eles compreendem fenômenos políticos como bolsonarismo e lulismo se relacionam de maneira singular com as formas através das quais eles enxergam seus 
movimentos pela cidade e suas experiências precárias. Somadas a isso, suas formas de autocompreensão vem à tona "tanto pelo desejo do motorista de ganhar bons conceitos quanto pelos limites de uma conversa delimitada no tempo" (Junge \& Tavares 2020:120) ${ }^{2}$.

Nesse sentido, mobilizo esse contexto etnográfico para evidenciar que ele permite a emergência de uma determinada maneira de se apreender a relação de uma infraestrutura específica com uma série de sujeitos marcados por subjetividades que aparecem no contexto interativo entre motorista e passageiro/antropólogo como um "impulso para ver a si mesmo e ao mundo sociopolítico de uma forma particular" (Junge \& Tavares 2020:120). Desse modo, o conteúdo de seus relatos ${ }^{3}$ advém de um contexto socioeconômico na qual os motoristas utilizam seus carros, comprados em um momento anterior à crise econômica na qual as possibilidades de acesso a crédito eram mais expansivas (Singer 2012; Junge \& Tavares 2020), para fazer frente a realidade de crescente desemprego. Ademais, os conhecimentos desses motoristas sobre as defasagens infraestruturais de Recife também aparecem como centrais na articulação de seus discursos sobre mobilidade uma vez que isso traz à tona quais os bairros que podem ser evitados pelos motoristas em suas circulações diárias. Explorar as possibilidades de um discurso construído no bojo dessa conjuntura pode fornecer importantes horizontes para se compreender uma nova forma de infraestrutura da mobilidade e suas relações com o espaço-tempo das cidades.

\section{Infraestrutura da mobilidade}

A configuração de uma infraestrutura faz emergir formas específicas de coletividades. Na questão da mobilidade urbana isso nos faz prestar atenção para como as infraestruturas modelam a forma do movimento de certas coletividades através da paisagem urbana ao nos dá condições de evidenciar que o circuito das interações que se formulam a partir de mobilidades específicas se constituem como tal a partir da maneira como certas infraestruturas permitem a reunião e circulação de bens, informações, pessoas e ideias (Larkin 2013). 
No artigo de Gabriel Luis Rosa (2012) sobre taxistas em Florianópolis, o autor nos evidencia como a rádio que reúne uma variedade de motoristas de táxi permite que eles troquem informações durante seu períodos de trabalho a fim de se protegerem de regiões de risco na cidade, construindo uma rede que possam auxiliá-los caso passem por assaltos ou problemas mecânicos com seus carros. Como relata o autor ao descrever a entrevista que fez com um dos interlocutores de sua pesquisa:

"No dia em que conversei com o mesmo, até as 23 horas já haviam ocorrido duas tentativas de assalto na cidade, fracassadas graças ao sistema de comunicação entre os motoristas, que possuem códigos específicos para alertar que estão em perigo para os colegas" (Rosa 2012:538).

Aqui, vemos que um tipo de solidariedade social entre motoristas de táxi é possível pela maneira como o rádio permite com que os taxistas interajam e façam circular informações específicas.

No trabalho de De Faria \& Kopper (2017) sobre o fenômeno popularizado como rolezinhos, a questão da infraestrutura parece atravessar o trabalho por dois eixos centrais. Primeiro, pela infraestrutura material em que os rolezinhos aconteciam, os shoppings centers de grandes centros urbanos no Brasil. Segundo, pelo aparelhamento sociotécnico que permitia que os rolezinhos fossem organizados, a saber redes sociais como Facebook. Assim, a maneira como essas duas infraestruturas constituem mutuamente um processo de movimento de informações (através das redes sociais) e pessoas (através da infraestrutura dos shopping centers) são aspectos fundamentais para as várias interpretações dos significados socioantropológicos desse fenômeno. Desse modo, De Faria \& Kopper mostraram como as formas de solidariedade que emergiram a partir da interação entre essas infraestruturas ${ }^{4}$ era um locus para se perceber uma mobilidade urbana que ensaiava o novo arranjamento de classe que ganhou forma com o lulismo (Singer 2012). Nesse sentido, uma das principais problematizações que os rolezinhos colocaram à baila foi como aqueles 
infraestruturas do consumo, ao serem habitados por jovens (em sua maioria negros) de periferia até então excluídos desses espaços foram vistas como um horizonte para se compreender qual era a forma de combate a desigualdade proposta pelo governo federal à época (uma ênfase na inclusão social através do acesso ao consumo) bem como quais eram os movimentos pela cidade que elas vinham acompanhados, a saber jovens que se organizavam por uma infraestrutura virtual e saiam de bairros periféricos para 'rolezar' em bairros de classe média. Embora as várias interpretações desse fenômeno não chegue a um consenso sobre seu significado político, todos eles reconhecem como as várias infraestruturas que o constituem permitem formas de associação específicas que se traduzem em modelos coletivos de movimento pela cidade.

Mesmo tratando de temáticas distintas, ambos os trabalhos demonstram como a interação entre infraestruturas específicas formulam coletividades singulares que se movem ao seu jeito pela cidade. De fato, os trabalhos evidenciam que a infraestrutura formula certas possibilidades de reunião, trocas simbólicas e movimento através da cidade. Nesse sentido, vemos aqui que as infraestruturas têm um papel ativo na maneira como atores políticos se associam tanto para reivindicar a presença em novos espaços quanto para elaborarem defesas sobre suas situações de trabalho.

\section{Trabalho platarformizado}

A precarização do trabalho no Brasil certamente não é inaugurada pelos trabalhadores por aplicativo, seja os entregadores de Rappi e Ifood ou os motoristas de Uber. De fato, em 'A política do precariado' (2013), Ruy Braga faz um breve apanhado histórico da precarização do trabalho brasileiro, discutindo desde a formação dos primeiros sindicatos no $\mathrm{ABC}$ paulista durante o governo Vargas até os trabalhadores das call centers que dominaram a cena do trabalho brasileiro na primeira década do século vinte e um. Assim, embora elementos como medo do desemprego, longas jornadas de trabalho 
e luta por redes de assistência social estivessem presentes em todas as fases descritas por Braga, elas aparecem através de formas específicas de interação entre os trabalhadores e destes para com as redes de comando e gerenciamento que os interpelam. Para as etnografias que acompanhavam essas trajetórias, uma questão central sempre foi a de formular categorias que pudessem descrever as relações que singularizam as distintas precarizações do trabalho.

Aqui, enxergar o aplicativo como uma infraestrutura que organiza, avalia e controla a rotina dos trabalhadores plataformizados parece ser aquilo que singulariza essa nova forma de precarização. Desse modo, o aplicativo parece ser o gestor do trabalhador ao impor o valor de seu trabalho (através dos preços das corridas sugeridos pelo aplicativo), ao fornecer um sistema em que ele vai ser avaliado pelos clientes e ao distribuir as solicitações das viagens de maneira específica através de uma variedade de motoristas. Assim, embora empresas como a Uber se apresentem como meros mediadores entre demanda de passageiros e oferta de motoristas (Slee 2017), a observação dos cotidianos desses trabalhadores permite evidenciar que a gramática de distribuição dessas informações, como mostrarei no desenrolar do texto, atende a uma forma específica de organização no sentido de maximizar as possibilidades de lucro para Uber e de diminuir as possibilidades de autonomia para os motoristas. De fato, expor essas dinâmicas de distribuição é tensionar a infraestrutura do aplicativo e mostrar que ela é menos algo que simplesmente está lá pronta para ser usada (Bowker et al 2010) do que algo que é atravessada por decisões políticas e administrativas que acabam por formular variadas formas de desigualdade. Assim, se esses aplicativos podem ser vistos como algo dado por seus usuários, a sua construção passa por processos complexos de debates entre desenvolvedores, engenheiros, técnicos e administradores. Mesmo que muitas vezes mascarados por um discurso meramente técnico, o resultado desse desenvolvimento produz consequências sociais, políticas e subjetivas em uma variedade de sujeitos sociais que são interpelados pelas ações desses aplicativos. Nesse sentido, enxergar as 
infraestruturas nos permite desvelar as razões políticas, éticas e sociais que foram tomadas na formulação de uma infraestrutura específica (Bowker et al 2010).

Nesse sentido, o esforço de Rosenblat \& Spark (2016) parece ser justamente o de mostrar, em experiências localizadas, como a interação dos motoristas com o aplicativo Uber é um locus para se observar as consequências políticas dessa infraestrutura da mobilidade. Assim, a partir de análises de posts dos motoristas de Uber em fóruns online e de entrevistas com motoristas feitas em algumas cidades nos Estados Unidos, ela faz uma análise detalhada de como os motoristas experienciam o trabalho sob o regime de distribuição de informações do aplicativo demonstrando, por exemplo, como a ausência do destino do percurso dos passageiros no aplicativo quando os motoristas aceitam uma viagem permite que estes corram o risco de aceitar corridas que podem não ser rentáveis a eles. Desse modo, por não ter acesso a essa informação os motoristas têm dificuldades em planejar os movimentos pela cidade no sentido de maximizar suas possibilidades de lucro. Sobre isso, fala um dos motoristas entrevistados pela antropóloga ao relatar sua decepção com essa dinâmica do aplicativo: "Você está dirigindo à cega. Quando acontece o chamado, você pode dirigir 15 minutos para levar alguém em uma distância de meia milha” (Rosenblat \& Spark 2016:3762). De fato, mesmo que o motorista queira recusar a viagem, ele corre o risco de ser desativado pela Uber como punição. Nesse sentido, mesmo que a Uber atraia os motoristas pela ideia de que eles podem programar seus cotidianos sem responder a uma estrutura hierarquia, a maneira com que a infraestrutura do aplicativo enquadra a informação distribuída permite que eles mesmos questionem a lógica da empresa:

"Se nós somos contratantes independentes, nós deveríamos ter o direito de recusar. Se eu olhar e ser 3:00 da tarde e o cara está indo para o JFK (aeroporto em Nova York), eu não vou aceitar. Quando eu chego na localização do cara e eu vou para o JFK, eu não vou querer fazer quarenta dólares por três horas de trabalho... Eles nos dizem que é nossa escolha quando nós queremos aceitar uma corri- 
da ou não, então como eles nos penalizam por isso?" (Rosenblat \& Spark 2016:3762). ${ }^{5}$

Aqui, vemos que o controle da circulação de informações do aplicativo formula um tipo específico de fragilização das relações de trabalho baseado no desconhecimento dos motoristas acerca do destino de suas mobilidades.

Outra maneira através da qual tal desigualdade informacional se faz presente no trabalho de Rosenblat é a partir do sistema de notas criado pelos desenvolvedores do aplicativo ao colocar a responsabilidade de avaliar o serviço de seus motoristas nos passageiros inscritos. Estes, depois que terminam sua viagem, são convidados pelo aplicativo a dar uma nota de um até cinco estrelas para os motoristas. Desse modo, se a média dos Ubers ao longo de um mês de trabalho for menor do que 4,6 eles começam a receber avisos da empresa e, caso as médias persistam, eles podem ser desativados do aplicativo. A partir dessa dinâmica, a Uber faz tanto seu controle de qualidade quanto se omite de contratar empregados que possam avaliar o desempenho de seus motoristas. Como aponta Rosenblat, a partir dessa relação é possível observar como as informações são distribuídas diferencialmente entre motoristas e passageiros já que enquanto aqueles desconhecem o próprio destino de suas viagens estes podem acompanhar todo o trajeto de seus motoristas e elaborar avaliações baseadas no acesso diferencial dessas informações.

Nesse sentido, se, por um lado, os aplicativos fornecem uma série de mecanismos através do qual os passageiros podem realizar suas avaliações, por outro, os motoristas têm frequentes restrições em questionar passageiros que o avaliem negativamente ou até mesmo em ter um conhecimento explícito do que os motivou em tais avaliações. Aqui, é importante evidenciar a constante ansiedade dos motoristas já que estes não podem saber qual passageiro (motivado por qual razão) poderia ter dado uma nota baixa a ele.

Nas entrevistas nas quais buscávamos relacionar percepções políticas aos relatos sobre precariedade enquanto os motoristas se mo- 
viam pela cidade, vimos essa insegurança plenamente manifesta em boa parte dos diálogos, como é o caso do motorista Alexandre, de 33 anos. Este, no momento em que a entrevista com ele foi realizada (setembro de 2018) ${ }^{6}$, estava trabalhando como motorista de Uber há cerca de três meses. Com uma nota média de 4,73 (portanto quase no limite de receber um 'recado da Uber'), Alexandre, mesmo relatando uma extensa rotina de trabalho (ele destaca como, mesmo quando está gripado ou com febre, chega em casa às vinte e duas horas e acorda no outro dia às quatro da manhã para começar a nova rotina de viagens), enxerga seu trabalho de forma positiva já que, ao ser "seu próprio patrão", ele poderia escolher "o dia e a hora que quer trabalhar" sem precisar responder à estruturas hierárquicas. De fato, como sintoma dessa possibilidade de escolha, ele relata como, depois de ser assaltado quando levava um passageiro durante a madrugada, mudou o turno em que trabalha apenas aceitando viagens que fossem até às vinte e três horas, "sem passar mais disso". No entanto, embora o senso de autovalorização esteja de certa forma presente, a ansiedade de não conseguir prever o comportamento de seus passageiros é algo frequente no relato de suas experiências cotidianas:

Pronto, essa semana eu fui reportado no sábado porque a mulher colocou mau cheiro no carro mas eu tenho cuidado, eu comprei essência, comprei álcool de fazer perfume para colocar no carro. Aí o carro tem perfume de carro e ela colocou que o carro estava com mau cheiro. Então a Uber ela não quer saber, se você chegar lá e colocar uma estrela ela não vai nem querer saber o que foi, às vezes ela dá a opção de você dizer, marcar lá né, quais foram os problemas mas simplesmente vai chegar lá e baixar a minha nota. Ela quer saber a opinião do passageiro, o motorista não tem direito a nada.

Se essa dinâmica é justificada pela empresa a partir de uma responsabilidade em proteger a identidade dos passageiros, ela, todavia, torna mais difícil para os motoristas perceberem o que poderia ter mudado em suas performances para justificar uma avaliação baixa (Rosenblat et al 2016). Além disso, as más avaliações também podem 
ser motivadas por fatores que não estão no controle dos motoristas. Como afirma Rosenblat et al:

"Alguns motoristas observam que eles recebem notas baixas como resposta a uma variedade de coisas que não está em seu controle, como: preços altos, mal funcionamento do GPS, passageiros que colocam locais errados de partida, pegar passageiros que não estejam em conformidade com as regras locais e da Uber como pegar mais passageiros do que a quantidade de cintos existentes no carro" (Rosenblat et al 2016:6).

Rosenblat ainda mostra como potenciais preconceitos de raça podem ser operacionalizados por tais desigualdades informacionais. Através de uma síntese de como tais preconceitos ocorrem em espaços virtuais de avaliação de serviços, a autora mostra como as avaliações no aplicativo Uber podem se relacionar com o que ela chama de uma avaliação enviesada por fatores raciais. Aqui, ela evidencia que a impessoalidade dada aos passageiros pela infraestrutura do aplicativo permite que a associação entre nota e raça não possa ser feita por instituições que mapeiam tais relações em arenas tradicionais de trabalho ao evidenciar que as próprias formas de controle e legislações existentes acerca da discriminação em ambientes de trabalho não conseguem se adereçar a um contexto formado tanto pela ausência de uma relação direta entre trabalhador e empresa (a partir da qual a responsabilidade do controle poderia ser atribuída a uma instância da relação) quanto pela impossibilidade de se associar uma avaliação potencialmente enviesada à um cliente específico (Rosenblat et al 2016). Assim, a própria dinâmica do aplicativo parece não admitir a possibilidade de que tais relações possam vir a atuar no processo de avaliação dos motoristas, não fornecendo interações através da qual os motoristas poderiam denunciar avaliações enviesadas por questões raciais ou por reclamações em relação a algo que não está no seu controle.

\section{Algoritmos, mobilidade urbana e as promessas da infraestrutura}

Como aponta a literatura sobre sociologia do trabalho, tais dinâmicas de circulação de informações na esfera do trabalho é "resultado 
de processos globais em curso há décadas e que envolvem transformações no controle, gerenciamento e organização do trabalho" (Abilio 2019:2) ${ }^{7}$. Nesse sentido, sendo a uberização (termo que parece sintetizar na esfera pública as dinâmicas descritas até aqui) uma consolidação de décadas de políticas neoliberais que envolvem a eliminação de direitos do trabalho e novas formas de subjetivação (Dardot et al 2016) ela, ao mesmo tempo, parece "materializar um novo estágio desse processo" (Abílio 2019:2) na medida em que, com uso das plataformas, dispersa o trabalho sem perder o controle sobre ele (Abílio

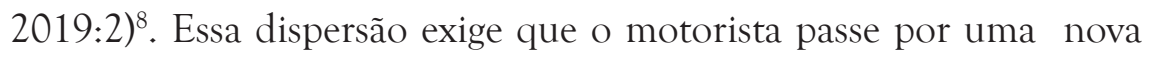
forma de recrutamento ao trabalho que não mais atende a um contrato entre diferentes instâncias (mesmo que sujeito a rotatividade) mas a uma lógica na qual ele precisa sempre estar disponível e conectado ao aplicativo mesmo sem saber a lógica de distribuição das suas viagens, de seus preços e de suas avaliações. Aqui, o trabalhador não é mais um contratado, mas alguém que, como afirma Abilio (2019), se engaja no trabalho.

Nesse contexto, o algoritmo, cuja operacionalidade não se abre para aqueles fora das centrais de gerência da Uber (Slee 2017), é o formulador de uma nova forma de mobilidade que nem se baseia em um reconhecimento coletivo de possibilidades de ascensão social como visto com os rolezinhos (De Faria et al 2017) nem em uma rede de comunicação comum que vise a defesa de situações de trabalho específicas como evidenciado a partir dos motoristas de táxi (Rosa 2012). De fato, o controle de dados feita pela empresa implica em um movimento pela cidade alienado que deságua em uma impossibilidade dos motoristas cumprirem o que parece ser tanto a lógica atrativa da empresa quanto a própria promessa das políticas neoliberais, a saber a ideia de que esses trabalhadores se tornem empresários de si mesmos, como aponta Alexandre. Nesse ponto, cabe trazer à tona as considerações de Pierre Dardot e Cristian Laval ao falarem que, além de uma política econômica que presume limites de gastos do Estado em políticas sociais, o neoliberalismo implica em formas específicas 
de governar a si mesmo no sentido de dimensionar todas as facetas da vida social como entidades que podem se traduzir em uma margem de lucro. Aqui, a empresa ocupa uma papel central nessa forma de governamentalidade ao se aproveitar de um contexto de medo da espoliação (já que as políticas de estado neoliberais se voltam para o corte de direitos sociais e trabalhistas) e traduzir isso em motivação para a construção de indivíduos em competição (Dardot et al 2016). Assim, a partir de um arcabouço de valores e princípios que envolvem a " energia, iniciativa, ambição, cálculo e responsabilidade" (Rose 1996 apud Dardot et al 2016:333) a empresa neoliberal conduz seus 'associados'9 como entidades que precisam inovar e redefinir seus objetivos continuadamente já que eles não possuem mais redes de assistência que poderiam protegê-los do desemprego e outras fragilidades sociais como doenças crônicas e acidentes de trabalho. Como afirmam Dardot \& Laval:

"Trata-se do indivíduo competente e competitivo, que procura maximizar seu capital humano em todos os campos, que não procura apenas projetar-se no futuro e calcular ganhos e custos como o velho homem econômico, mas que procura sobretudo trabalhar a si mesmo com o intuito de transformar-se continuamente, aprimorar-se, tornar-se sempre mais eficaz. $\mathrm{O}$ que distingue esse sujeito é o próprio processo de aprimoramento que ele realiza sobre si mesmo, levando -o a melhorar incessantemente seus resultados e seus desempenhos" (Dardot et al 2016:333).

No neoliberalismo, esse modo de gerência não parte apenas da empresa mas se torna o objetivo de vida do próprio sujeito que presta serviços de modo que objetivo empresarial e pessoal aparecem socialmente como um só. Já que habita em contexto de inseguridade social, os riscos dessa nova forma de gerência caem sobre as costas do trabalhador que se utiliza desse mesmo afeto como motivador de suas ações e de suas dinâmicas. Ademais, a busca por inovação aparece como fundamento central para conseguir se situar em um mundo de ausência de redes de assistência (Slee 2017; Antunes 2018), este termo permite que essas empresas se omitam juridicamente de um arcabou- 
ço de responsabilidades jurídicas para com seus contratados. Como mostram vários estudos na Uber, o envolvimento nessas dinâmicas se dá a partir dos disparos de mensagem feitos pela infraestrutura do aplicativo a partir do qual a empresa monitora o desempenho dos motoristas. Assim, se eles estiverem com uma sequência de notas negativas $^{10}$, os aplicativos enviam mensagens com recomendações de como o motorista poderia 'inovar' ou se 'reinventar' para reconquistar uma boa média. Sobre essa dinâmica de envio, Rosenblat et al (2016) nos diz algo relevante:

"Enquanto o sistema de notas avisa a Uber sobre motoristas que tenham uma performance insuficiente, ela também provêem um contexto através do qual a Uber pode comunicar comportamentos desejáveis para seus motoristas. Isso pode vir na forma de notas genéricas que listam uma série de bons e maus comportamentos ou referências até comentários específicos dos usuários como 'você recebeu um aviso por falar demais'. Os motoristas que recebem essa notificação são redirecionados para um site que fornece a eles conselhos detalhados para as interações durante as viagens, como 'se eles não estiverem engajando com a conversa, o silêncio pode ser a chave aqui'" (Rosenblat et al 2016:5).

Aqui, tais mensagens fazem a gerência das mínimas atitudes dos motoristas no sentido de estimulá-los a racionalizar cada aspecto de seus comportamentos. Para tanto, o aplicativo ainda envia as notas dos motoristas mais bem ranqueados na empresa em uma dada região (com os elogios recebidos por estes no aplicativo) (Rosenblat et al 2016), para estimular outros motoristas a melhorarem seus respectivos desempenhos. Nesse ponto, a ideia de Dardot \& Laval (2016) de que os trabalhadores se tornam entes em constante competição parece particularmente adequada.

Ainda como forma de controle, a Uber também pode mudar o status dos motoristas de Uber no aplicativo de modo a fazer com que ele saia da categoria 'Uberx' (motoristas que recebem maiores quantias por viagens) e volte a ser um Uber comum. Portanto, o controle de qualidade é feito por um gerenciamento algorítmico que controla 
o desempenho dos motoristas seja através do envio de 'mensagens de desempenho', seja através de estímulos e bonificações por desempenhos mais bem geridos.

No entanto, se a infraestrutura do aplicativo conduz o processo de neoliberalização do trabalho desses motoristas por estímulos flexíveis ao controle de desempenho, ela também impede que as informações do aplicativo circulem de forma a dar condições desses motoristas a racionalizarem seus desempenhos. Portanto, como as dinâmicas dos algoritmos não são reveladas aos motoristas (e, por conseguinte, a lógica de aumento ou diminuição de preço das viagens a depender da hora e/ou região da cidade) os motoristas conduzem seus movimentos baseados em conhecimentos tácitos sobre suas próprias rotinas enquanto motoristas e o que, a partir delas, poderia levar a melhoria da renda adquirida por dia de circulação. Essa racionalização do trabalho que parece ser baseada em uma distribuição seletiva das informações do aplicativo faz emergir um tipo de mobilidade que chamo aqui de mobilidade alienada. Alienada porque os sujeitos que atravessam a cidade a partir dessa dinâmica estão alheios ao arcabouço de informações que constituem suas rotinas e seus movimentos pela malha urbana. Aqui, o gerenciamento algorítmico parece conduzir um processo de estranhamento do motorista em relação a cidade em que ele mesmo circula. Podemos ver essa percepção plenamente manifesta quando os motoristas, já que só podem cancelar uma quantidade limitada de viagens (importante lembrar que se tiver muitos cancelamentos o motorista pode ser desligado da Uber), são obrigados a entrar em regiões da cidade desconhecidas por eles, o que implica em riscos com multas de trânsito e entrada em áreas violentas. Se os seus conhecimentos tácitos como motorista podem preveni-los desses infortúnios, esses saberes também trazem consequências para seu processo avaliativo no aplicativo.

Acerca disso, o motorista Roberval, de 29 anos, diz algo esclarecedor. Ex-operador de Telemarketing (quando foi demitido assim que a crise econômica de 2016 se aprofundou), Roberval é motoris- 
ta de Uber (com um nota média no aplicativo de 4,83) há cerca de oito meses. Como precisa dividir o tempo enquanto motorista com sua faculdade de telemarketing (que ele cursa online), Roberval tenta construir uma rotina que, por um lado, dê condições de alcançar a meta de renda posta por ele diariamente e, por outro, de cursar sua faculdade bem como manter hábitos saudáveis como ter uma rotina na academia e ter tempo para cozinhar "um negócio mais saudável" como "um arroz integral e um peito de frango grelhado". No entanto, conseguir atender a essas dimensões exige dele um aprendizado diário acerca dos melhores horários e regiões da cidade para circular:

Todo dia eu aprendo. Hoje mesmo eu estava fazendo uma meta de fazer duzentos e setenta reais, né? Setenta de combustível e duzentos por gás. Aí o que é que eu faço, eu saía de sete da manhã e ia até dez da noite, onze horas da noite, trabalhava doze catorze horas por dia. E às vezes eu não conseguia fazer esse dinheiro. Aí hoje em dia eu criei outro método, né? Primeiro eu saio de manhãzinha de seis...seis e meia eu saio. Aí eu fico rodando até dez horas da noite/ dez da manhã, né?

Nesse sentido, Roberval relaciona os conhecimentos acerca dos horários mais rentáveis para circular com os das regiões que geralmente diminuem as suas notas:

Aí eu deixei de rodar mesmo nesses locais assim de zona subúrbio e zona periférica. Aí minha nota melhorou bastante, entendeu? Eu descia, eu abria e lá é muito morro, muita ladeira, tem local de difícil acesso que a gente não tem como entrar, aí o cliente não entende isso, aí ele pega e dá uma nota baixa de pirraça. Aí a nota baixa pra gente prejudica muito.

Nesse relato, vemos a tentativa do motorista em se desvencilhar da mobilidade sugerida pelo gerenciamento algorítmico ser punida pela própria dinâmica de notas estabelecida pelo aplicativo. Aqui, se uma possibilidade de compreensão das infraestruturas é buscar entender o que elas prometem enxergando como certas moralidades atuam na formulação dessas promessas (Appel et al 2018) vemos aqui que ela também impossibilita o desdobramento das mesmas racionalidades 
que elas colocam como desejáveis. Nesse sentido, mais uma vez a ideia de empresário autônomo, prometida pela empresa como um atrativo para novos motoristas (Slee 2017), é contraposta à um modelo de gerência que não fornece ao motorista possibilidades de conduzir individualmente uma rotina que escape das dinâmicas de comando do aplicativo. Essa impossibilidade é algo constitutivo de um gerenciamento que organiza a mobilidade pela cidade no sentido de inviabilizar as possibilidades de autonomia acerca do tipo de circulação que será assumida uma vez que os espaços para criatividade e inovação (Dardot et al 2016) aparecem infraestruturalmente inviabilizados.

No entanto, as circunstâncias etnográficas a que tive acesso também puderam nos dar um outro eixo de possibilidades para analisar essa questão. Desse modo, outra temática relevante para o desvelamento das infraestruturas é o de como suas promessas se adereçam a certos sujeitos marginalizados que estão situados em condições sociais específicas (Appel et al 2018). Aqui, a experiência etnográfica parece ser uma forma de observar como as infraestruturas são mobilizadas a partir de determinadas circunstâncias de interação. De fato, apenas tratando as infraestruturas como algo relacional (Appel et al 2018) se é possível desvelar as condições de resistência de certos sujeitos sociais às infraestruturas que modelam suas respectivas precariedades. Nessa pesquisa, isso está manifestado na maneira como o motorista Roberto, através de conhecimentos tácitos sobre a cidade do Recife, desvia de certas regiões consideradas por ele como perigosas. Roberto, de 32 anos, tem uma nota média no aplicativo de 4.95 e é motorista do Uber há cerca de quatro meses. Antes de se tornar motorista, Roberto trabalhava em uma empresa (que ele opta por não descrever detalhadamente) há cerca de quatro anos. Depois de ter recebido promessas não cumpridas pelo seu ex-chefe, Roberto pede demissão e decide abrir sua própria empresa. Para conseguir arcar com os investimentos iniciais de seu novo negócio, Roberto decide rodar como Uber muito embora ache que é apenas um trabalho temporário até que ele consiga 'alavancar' seu empreendimento. Mesmo estando apenas em 
seu quarto mês enquanto motorista e enxergando esse trabalho como algo temporário, Roberto compartilha alguns dos conhecimentos que já acumulou em seu ir e vir pela cidade. Nesse sentido, ele relata, a partir de um diagnóstico das regiões potencialmente perigosas, alguns dos 'macetes' que adquiriu:

Várzea é muito perigoso ali. Tem que andar com um olho no padre e outro na missa. É muito perigoso ali a Várzea. Muito assalto, tanta coisa, você sai do seu trabalho, você cumpriru sua meta, sua jornada de trabalho. Vem um assaltante, vai e lhe mata...

Ao relatar como ele lida com essa região, assim nos falou o mesmo condutor:

Para quem roda de Uber existem algumas dicas, né? Alguns macetes que você vai fazendo e consegue evitar. Se é uma localidade que a gente conhece que tem um grau de periculosidade perigoso aí, por exemplo, eu vou deixar você lá. Tudo bem, eu deixo. Mas quando te deixar lá, eu desligo o aplicativo e saio logo de lá para não receber outras corridas pra lá.

Assim, a partir de uma associação entre conhecimento geográfico da violência urbana de Recife com habilidades para se interagir com o aplicativo, Roberto encontra meios de desviar do controle algorítmico. Nesse sentido, a experiência local dos motoristas nos dá condições de entender como essas infraestruturas são mobilizadas, modeladas ou até mesmo burladas pelas vivências de sujeitos sociais marcados por experiências de precariedade situadas em um contexto urbano de medo da violência.

Além disso, a ênfase na circunstância etnográfica traz a tona a maneira com que os motoristas, em suas interações com as infraestruturas, reorganizam as experiências no espaço/tempo (Appel et al 2018) tal qual são sujeitas inicialmente à eles pelo gerenciamento algorítmico. Desse modo, se, por um lado, os aplicativos podem ser lidos como instâncias que comprimem o espaço/tempo, conectando motoristas e passageiros através de uma operação algorítmica que faz com que ambos circulem por determinados espaços por certos perío- 
dos de tempo, por outro, as ações de motoristas como aquela descrita anteriormente fazem com que certas gramáticas de circulação espacial possam ser rompidas. Nesse sentido, podemos pensar nessas ações como micropoliticas através das quais os motoristas amenizam sua realidade precária, exibindo uma certa agência frente às infraestruturas. Ademais, essas respostas dos motoristas às dinâmicas do aplicativo nos permitem tensionar a noção de mobilidade alienada e nos levar a questionamentos como: Que tipos de saberes sobre a cidade podem emergir de uma experiência de controle algorítmico?

Além das especificidades urbanas de Recife, as singularidades do contexto econômico brasileiro, na qual o índice de desemprego em 2016 chega na casa dos 12\% (Reuters 2017) com baixas diminuições nos anos seguintes, permite que a possibilidade de circular com a Uber seja assimilada por boa parte dos motoristas entrevistados por mim como um alívio perante o medo crescente do desemprego. Desse modo, nos relatos que abordam o contexto de inscrição na Uber, esses motoristas exibem reflexões como: "eu tava trabalhando só que aí eu fui demitido, aí eu decidi começar a rodar de Uber para tentar conseguir...manter as contas em dia" ou "tava desempregado aí...apareceu a oportunidade, né? de trabalhar". Nesse sentido, os receios de ser incapaz de arcar com despesas básicas permitem uma determinada maneira de subjetivar a forma de trabalho que os aplicativos propõem a esses motoristas. Portanto, estimulados a falar sobre o contexto econômico político, haja visto o contexto em que essas entrevistas foram realizadas, esses motoristas elaboram esforços para entender como a Uber se insere tanto em suas vivências circulando pela malha urbana de Recife quanto nas precariedades geradas por uma crise político-econômica que se alastrou no Brasil.

Em suma, a importância de um conhecimento geopoliticamente localizado para o tipo de questão que se formula acerca da infraestrutura dos aplicativos de corrida compartilhada parece ser o desafio para antropólogas e antropólogos que queiram desenvolver análises significativas nessa área. Nesse sentido, assim como mostrei que as 
questões mobilizadas pelos motoristas de Uber entrevistados por mim se relacionam com realidades urbanas e nacionais singulares, os motoristas entrevistados por Rosenblat também se referem a contextos localizados quando, por exemplo, um deles se decepciona em aceitar uma viagem que o leva até aeroporto de Nova York. No entanto, o desafio específico dos pesquisadores do sul precisa ser o de ter sensibilidade para buscar relações entre temáticas que constituem a relação dos motoristas com a geografia urbana das cidades dessa região (como violência e precariedade das pistas com seus aclives, declives, morros e regiões de difícil acesso) e as questões político-econômicas dos países situados na periferia do capitalismo que influem nas maneiras com as quais esses motoristas se enxergam enquanto trabalhadores plataformizados.

\section{Podem os algoritmos servirem a uma política democrática da cidade?}

O corte analítico entre mobilidade e trabalho que utilizamos no desenrolar deste artigo nos fornece uma possibilidade de se adereçar àqueles que veem nos serviços de corrida compartilhada um caminho para democratizar o espaço urbano. Os defensores dessa tese afirmam que os baixos preços da Uber em comparação com os táxis permitem que indivíduos se locomovam pela cidade com apenas a pressuposição de que tenham o aplicativo baixado em seus smartphones. Isso é criticável, sobretudo, porque coloca como auto evidente a capacidade de uma variedade de sujeitos, advindas de uma série de locais sociais distintos, em interagir com as especificidades dessa infraestrutura. Vemos isso seja na pressuposição de que todos teriam acesso a uma rede 3G/4G capaz de suportar o aplicativo em seus celulares ou nas considerações de que indivíduos desacostumados com tais tecnologias poderiam solicitar ou cancelar uma viagem sem maiores dificuldades. Além disso, os 'preços baixos' estão na verdade sujeitos ao tipo de mediação entre demanda e oferta tal como é feito pelos algoritmos das empresas de modo que, a depender desses fatores, o preço do 
percurso de uma área à outra da cidade pode aumentar ou diminuir por razões que não aparecem de forma clara. Por conseguinte, este fator pode inviabilizar com que uma variedade de indivíduos arquem com os preços alcançados por essas constantes flutuações. Isso parece se exacerbar ainda mais quando consideramos, como um dos motoristas citados anteriormente sugere, que eles deixam de atuar em certas áreas da cidade por considerarem elas como perigosas ou de difícil acesso de modo a tornar inviável a oferta dos serviços da Uber para os habitantes de locais como estes.

Portanto, tal 'democratização do espaço urbano' parece estar absolutamente sujeita a um ente cuja operacionalidade não está aberta nem a motoristas, nem a passageiros e nem aos atores públicos. Nesse ponto, cabe voltar a citação inicial de Bruno Latour. Ali o autor aponta para a ideia de que um coletivo que possa servir a vivência democrática precisa estar apto a reconhecer seus limites internos e as controvérsias que sempre o posicionam de maneira instável e o fazem estar em um constante mapeamento de novas entidades que possam dar algum tipo de resposta (sempre provisória e limitada) às suas controvérsias. Aqui, a ideia de democracia emerge menos da ideia de uma democracia formal já constituída (típica da ideia de democracia liberal) do que de um movimento de busca ininterrupta por novas associações entre humanos e não-humanos que possam desvelar os portavozes que falam pelas novas entidades capazes de tensionar a pretensa estabilidade do coletivo. Para ele, a presença dessas entidades, depois de descobertas, deveriam necessariamente passar por um processo de provação na vida pública nas quais suas condições de inserção e seus efeitos para o coletivo poderiam ser discutidos e, por conseguinte, aceitos ou renegados. Para tanto, ele faz referência a necessidade de acompanhar "os conhecimentos de administradores, cientistas, políticos, economistas e moralistas" (Latour 2018:286) como pré-condição para se compreender o que está em jogo na constituição desses coletivos. Em nosso contexto, essa reflexão nos remete a necessidade dos esforços de intelectuais, movimentos sociais e instituições de Estado em 
mapear e trazer à cena pública os conhecimentos de programadores, designers, administradores e ceo's responsáveis pela construção e viabilização coletiva dos algoritmos que modelam as vivências descritas nesse artigo de modo a colocar esses saberes menos como algo dado do que como algo que coloca sucessivas controvérsias para a disputa pública acerca das formas de mobilidade urbana. Assim, se quisermos colocar esses aplicativos e seus algoritmos como entidades que podem de fato servir a vivência democrática da cidade, eles precisam estar em outras condições de abertura para a sociedade civil e suas organizações. Por fim, a necessidade de um esforço como esse coloca em cena um novo horizonte para se compreender em quais termos a questão do direito à cidade está inserido.

\section{Considerações finais}

Assumir a definição de infraestrutura proposta por Brian Larkin (2013) citada no início do texto para se compreender a mobilidade urbana nos dá possibilidade de mapear que tipo de movimento (acompanhada de quais sentimentos coletivos e racionalidades) emergem a partir das formas através das quais certas infraestruturas organizam a circulação de informações e pessoas (Larkin 2013). Assim, se os shopping centers aliadas às redes sociais apareciam como entidades que permitiam que certo sentimento de classe pudesse ser performado (De Faria et al 2017) ou as rádios dos taxistas permitiam que estes se interligassem na vivência de uma mesma realidade laboral (Rosa 2012), os aplicativos aparecem como infraestruturas nas quais, ao alienarem os motoristas da própria vivência urbana, inviabilizam as possibilidades de associação coletiva. Isso se justifica não apenas pela impossibilidade dos aplicativos em conectar os motoristas, mas também a partir da maneira através da qual o algoritmo da Uber organiza e controla o trabalho entre os motoristas. Nesse sentido, nas mensagens disparadas pela empresa (Rosenblat \& Spark 2016), como foi dito anteriormente, o desempenho dos trabalhadores conectados circulam por eles com o intuito menos de proporcionar a emergência de alguma forma de as- 
sistência mútua do que para servir como estímulo para a competição entre os próprios motoristas. Assim, a infraestrutura algorítmica que busquei descrever até aqui parece basear seu gerenciamento em duas dimensões que se retroalimentam. Por um lado, na impossibilidade dos Ubers conduzirem seus movimentos urbanos de forma autônoma e, por outro, na gerência de uma forma laboral ausente de garantias, sejam elas uma renda básica ou uma possibilidade de associação com um outro imerso em situações laborais semelhantes. No entanto, através de vivências geopoliticamente localizadas, a pesquisa feita com os Ubers me mostrou que embora alienados do conhecimento de suas mobilidades, os motoristas, mesmo sem possibilidades de se associar coletivamente, conseguem elaborar formas de burlar essas infraestruturas da mobilidade, dando uma latência especifica as operações sugeridas pelo aplicativo. Aqui, aparece um desafio central para aqueles que queiram realizar pesquisas sobre o trabalho plataformizado, o de localizá-lo em sua relacionalidade com certos contextos urbanos e realidades político-econômicas.

Ademais, a aproximação entre infraestrutura do trabalho e mobilidade permitiu evidenciar como uma específica experiência de precarização modela um certo tipo de movimento pela cidade que se torna possível pelas formas com as quais os aplicativos tanto organizam as informações distribuídas quanto a partir dos modelos de interação que eles colocam como possíveis para passageiros e motoristas. Assim, esse movimento cortado por uma forma laboral que tem como organizador de suas dinâmicas a desigualdade informacional abre um novo horizonte para se pensar a mobilidade urbana. Esse entrecruzamento pode levar a questões ricas como, por exemplo, quais os desafios de se conduzir uma política de planejamento urbano a partir de um gerenciamento algorítmico que tem suas dinâmicas restritas aos programadores e desenvolvedores das empresas de tecnologia? Ou, com essa realidade configurada, quais as dificuldades que se colocam ao Estado para se mapear e, por conseguinte, construir planos de enfrentamento às arbitrariedades vividas pelos motoristas de Uber como, por exem- 
plo, as variadas consequências do racismo algorítmico ${ }^{11}$ ? Um possível caminho para a resposta dessas perguntas pressupõe necessariamente a capacidade dos movimentos sociais que reinvidicam o direito à cidade bem com as pautas de democratização dos seus espaços e de seus serviços públicos em colocar na ordem do dia a agenda do que Morozov \& Bria (2020) descrevem como soberania digital. Para os autores, esse termo aponta para a "capacidade dos cidadãos de terem voz e de participarem na operação e na destinação das infraestruturas tecnológicas que os rodeiam” (Morozov \& Bria 2020:80) de modo que os dados que servem ao controle privado de um punhado de empresas se traduzam em informações capazes de sanar os graves problemas causados por políticas neoliberais nos serviços públicos das grandes cidades brasileiras. Nesse sentido, a soberania digital exige uma crítica radical do neoliberalismo e da sua proposta política de resolução privada de problemas públicos como a ideia de que aplicativos como a Uber resolveriam tanto a questão do desemprego para os motoristas inscritos na empresa quanto poderiam fornecer acesso ao transporte para população. Como foi argumentado ao longo deste artigo, essas soluções se constituem pela exclusão de parcelas significativas das classes populares e de suas inserções específicas no espaço urbano bem como pela reprodução e aprofundamento de um trabalho precarizado que emerge justamente da apropriação privada das informações criadas pela interação de motoristas e passageiros quando estes solicitam e aceitam viagens pela infraestrutura do aplicativo.

Nesse sentido Morozov \& Bria (2020) apresentam propostas relevantes no sentido de desalienar essas informações como, por exemplo, a instauração de códigos abertos para os aplicativos de corrida ou a construção de conselhos populares em âmbito municipal através dos quais as informações de empresas como a Uber poderiam servir às necessidades concretas dos usuários de transporte público, dos comerciantes informais e dos gestores municipais. Em um país de capitalismo periférico e dependente como o Brasil onde empresas multinacionais se inserem almejando expandir seu mercado e sua taxa de 
lucro (inclusive através da variedade de informações produzidas pelas interações dos trabalhadores com as plataformas digitais que organizam sua própria exploração), o projeto de soberania tecnológica tem relação intrínseca com o de soberania nacional.

\section{Notas:}

1 Esse artigo não poderia ter sido feito sem a parceria com o professor Benjamin Junge que, gentilmente, me concedeu a permissão para utilizar os dados de uma outra pesquisa que realizamos sobre motoristas de Uber e percepções políticas (Junge \& Tavares 2020).

2 Estudo recentemente publicado pela revista novos estudos Cebrap (Junge \& Tavares 2020) presidenciais de 2018 (Junge \& Tavares 2020).

3 O período de realização dessas entrevistas foi justamente durante as semanas que antecederam o primeiro turno das eleições presidenciais. Esse contexto parecia estimular os motoristas a discutirem questões sobre política e economia.

4 Os autores mostram, por exemplo, como os vídeos dos rolezinhos circulavam por grupos de facebook e como as lideranças desse movimento se popularizaram pelo compartilhamento dessas imagens.

5 Tanto este trecho quanto todos os outros dos artigos de Rosenblat foram traduzidos pelo autor.

6 Quando relatamos o tempo enquanto motorista de Uber dos interlocutores desta pesquisa, nos referenciamos sempre do período de motorista até a realização das entrevistas (Setembro e Outubro de 2018).

7 Embora a literatura sobre a precarização do trabalho aponte que no caso brasileiro os governos Lula e Dilma significaram um freio frente a essas políticas, é possível demonstrar novas categorias laborais que se expandiram durante esses governos (como os trabalhadores de call centers e as revendedoras da avon) que parecem exprimir de forma significativa o processo descrito por Abílio.

8 Portanto, a novidade aqui é menos a eliminação de direitos (embora esta se consolide) do que o novo tipo de gerência do trabalho que emerge a partir do trabalho mediado pelas plataformas digitais.

9 Aqui, mobilizamos o termo associado em aspas para descrever a maneira como a empresa neoliberal descreve sua associação com os trabalhadores.

10 Entendemos aqui nota negativa como aquelas abaixo da média aceita para que os motoristas prossigam inscritos na Uber. Essas notas podem variar de 4,5 até 4,7, a depender da cidade.

11 Termo que se refere a forma como os algoritmos permitem a emergência de dinâmicas sociais racializadas. O estudo de Tarcísio Silva (2020) é ilustrativo nos 
vários desdobramentos dessa questão ao mostrar, a partir do conceito de microagressões, como os algoritmos da google permitem que empresas exibam anúncios de crimes para usuários afroamericanos.

\section{Referências:}

ABÍLIO, L. 2017. Uberização do trabalho: A subsunção real da viração. (https:// blogdaboitempo.com.br/2017/02/22/uberizacao-do-trabalho-subsuncao-realda-viracao/; acesso em 27/03/2021). . 2018. "Uberização e viração: mulheres periféricas no centro da acumulação capitalista”. Revista Margem Esquerda, 31:54-61.

. 2019. "Uberização: Do empreendedorismo para o autogerenciamento subordinado". Revista Psicoperspectivas, 18(3):41-51.

. 2020. "Plataforma digitais e uberização: Globalização de um sul administrado?". Contracampo, 39(1):12-26.

ANTUNES, R. 2018. O privilégio da servidão: o novo proletariado de serviços na era digital. São Paulo: Boitempo.

APPEL, H., ANAND, N. \& GUPTA, A. 2018. "Introduction: Temporality, politics, and the promise of infrastructure". In APPEL, H., ANAND, N. \& GUPTA, A. (eds): The promise of infrastructure, pp. 1-38. Duke: Duke University Press.

BOWKER, G. C. et al. 2010. "Toward information infrastructure studies: Ways of knowing in a networked environment". In HUNSINGER, J. et al (eds.): International Handbook of Internet Research, pp. 97-117. London: Springer.

BRAGA, R. 2013. A politica o precariado: Do populismo à hegemonia lulista. São Paulo: Boitempo.

DE FARIA, L. \& KOPPER, M. 2017. "Os rolezinhos e as metamorfoses do urbano no Brasil contemporâneo”. Anuário Antropológico, 42(2):239-266.

JUNGE, B. \& TAVARES, A. 2020. "Subjetividades Móveis: sentidos de periferia e percepções da crise entre motoristas de uber em Recife". Novos Estudos CEBRAP, 39(1):03-123.

LARKIN, B. 2013. "The politics and the poetics of infrastructure". Annu. Rev. Anthropol., 42:327-343.

LATOUR, B. 2019. Políticas da natureza: Como associar as ciências à democracia. São Paulo: Unesp.

LAVAL, C. \& DARDOT, P. 2016. A nova razão do mundo: Ensaio sobre a sociedade neoliberal. São Paulo, Brasil: Boitempo.

MOROZOV, E. \& BRIA, F. 2020. A cidade inteligente. Tecnologias urbanas e democracia. São Paulo: Ubu. 
REUTERS. 2017. Brasil fecha 2016 com recorde de 12,3 milhões de desempregados. Exame. (https://exame.com/economia/brasil-tem-desemprego-de-120-no-triate-dezembro-diz-ibge/; acesso em 28/06/2020).

ROSE, N. 1996. Inventing Our Selves: Psychology, Power and Personhood. Cambridge: Cambridge University Press.

ROSENBLAT, A. 2018. Uberland: How algorithms are rewriting the rules of work. Oakland: University of Californa Press.

ROSENBLAT, A. \& STARK, L. 2016. "Algorithmic Labor and information Asymmetries: A case study of Uber's drivers". International Journal of Communication, $10\left(^{*}\right): 3758-3784$.

ROSENBLAT, A. et al. 2016. Discriminating tastes: Customer ratings as vehicles for bias. (https://datasociety.net/pubs/ia/Discriminating_Tastes_Customer_ Ratings_as_Vehicles_for_Bias.pdf; acesso em 27/03/2021).

STAR, S. L. 1999. "The ethnography of infrastructure”. American Behavioral Scientist, 43:377-91.

SILVA, T. 2020. "Racismo algorítmico em plataformas digitais: Microagressões e discriminação em código". In SILVA, T. (ed.): Comunidades, algoritmos e ativismos digitais: Olhares afrodiaspóricos, pp. 120-137. São Paulo, Brasil: Literarua.

SINGER, A. 2012. Os sentidos do lulismo. São Paulo: Companhia das letras.

SLEE, T. 2017. Uberização: A nova onda do trabalho precarizado. São Paulo: Elefante.

Abstract: This article aims to analyze how the infrastructures of shared running applications allow a specific type of movement through the urban network. So, through a revisit of how the issue of infrastructure is present in some works in Urban Anthropology, I discuss how application infrastructure poses a series of new questions for understanding mobility (such as the idea that ride-sharing drivers, immersed in a precarious situation, move in an alienated way through the city) that overflow the previous analysis on this subject. Furthermore, from a specific ethnographic context, I show how a perspective from cities in the global south can raise new questions about the contradictory relationship between drivers and the racing apps that challenge them. Finally, I suggest that the information distribution dynamics of these infrastructures go against a democratic experience of the city.

Keywords: Infrastructure, Mobility, Precariousness, Global south.

Recebido em setembro de 2020. Aprovado em outubro 2020. 